\title{
Managing hyperemesis gravidarum: a multimodal challenge
}

\author{
JK Jueckstock, R Kaestner and I Mylonas*
}

\begin{abstract}
Up to $90 \%$ of pregnant women experience nausea and vomiting. When prolonged or severe, this is known as hyperemesis gravidarum ( $\mathrm{HG}$ ), which can, in individual cases, be life threatening. In this article the aetiology, diagnosis and treatment strategies will be presented based on a selective literature review. Treatment strategies range from outpatient dietary advice and antiemetic drugs to hospitalization and intravenous (IV) fluid replacement in persistent or severe cases. Alternative methods, such as acupuncture, are not yet evidence based but sometimes have a therapeutic effect.

In most cases, the condition is self limiting and subsides by around 20 weeks gestation. More severe forms require medical intervention once other organic causes of nausea and vomiting have been excluded. In addition, a psychosomatic approach is often helpful.

In view of its potential complexity, general practitioners and obstetricians should be well informed about HG and therapy should be multimodal.
\end{abstract}

\section{Introduction}

About $50 \%-90 \%$ of all pregnancies are accompanied by nausea and vomiting [1]. According to a study of more than 360 pregnant women, only $2 \%$ experienced only nausea in the morning whereas, in $80 \%$, complaints persisted throughout the day. The condition is usually selflimiting and peaks at around 9 weeks gestation. At 20 weeks symptoms typically cease. However, in up to $20 \%$ of cases, nausea and vomiting may continue until delivery [1].

This condition is known as nausea and vomiting during pregnancy (NVP) or emesis gravidarum and is of no pathological significance as long as the affected women do not feel unwell or restricted in their daily life [2]. There are, however, different grades in the scope of NVP, which range from occasional morning-sickness to excessive vomiting that persists throughout the day. The most severe grade of NVP often leads to hyperemesis gravidarum (HG; see below), but it can be difficult to differentiate between the two conditions.

A prospective study of more than 9000 pregnant women showed that NVP occurred significantly more

* Correspondence: ioannis.mylonas@med.uni-muenchen.de

1 First Department of Obstetrics and Gynaecology, Campus Innenstadt, Ludwig-Maximilians-University, Maistrasse 11, 80337 Munich, Germany Full list of author information is available at the end of the article often in primigravidas and in women who were less educated, younger, non-smokers and overweight or obese. The incidence of NVP was also higher in women with a history of nausea and vomiting in a previous pregnancy [3].

In order to exclude differential diagnoses the following crucial parameters should be investigated: Onset of nausea and vomiting (nearly all of the cases begin before 9 weeks of gestation), attendant symptoms, underlying chronic disorders or, in rare cases, hereditary diseases (see Figures 1 and 2) [4].

A small percentage of pregnant women experience a severe form of nausea and vomiting that is termed HG (synonym: excessive vomiting during pregnancy). This disorder has an estimated incidence of $0.5 \%-2 \%$ of all live births [5]. A standard definition of HG is the occurrence of more than three episodes of vomiting per day with ketonuria and more than $3 \mathrm{~kg}$ or $5 \%$ weight loss. However, the diagnosis is usually made clinically following the exclusion of other causes [6,7].

HG can, in individual cases, be life threatening and treatment must be initiated immediately. Clinical findings include dehydration, acidosis due to inadequate nutrition, alkalosis due to loss of hydrochloride and hypokalaemia. There are two degrees of severity: (i) grade 1 , nausea and vomiting without metabolic imbalance; and 

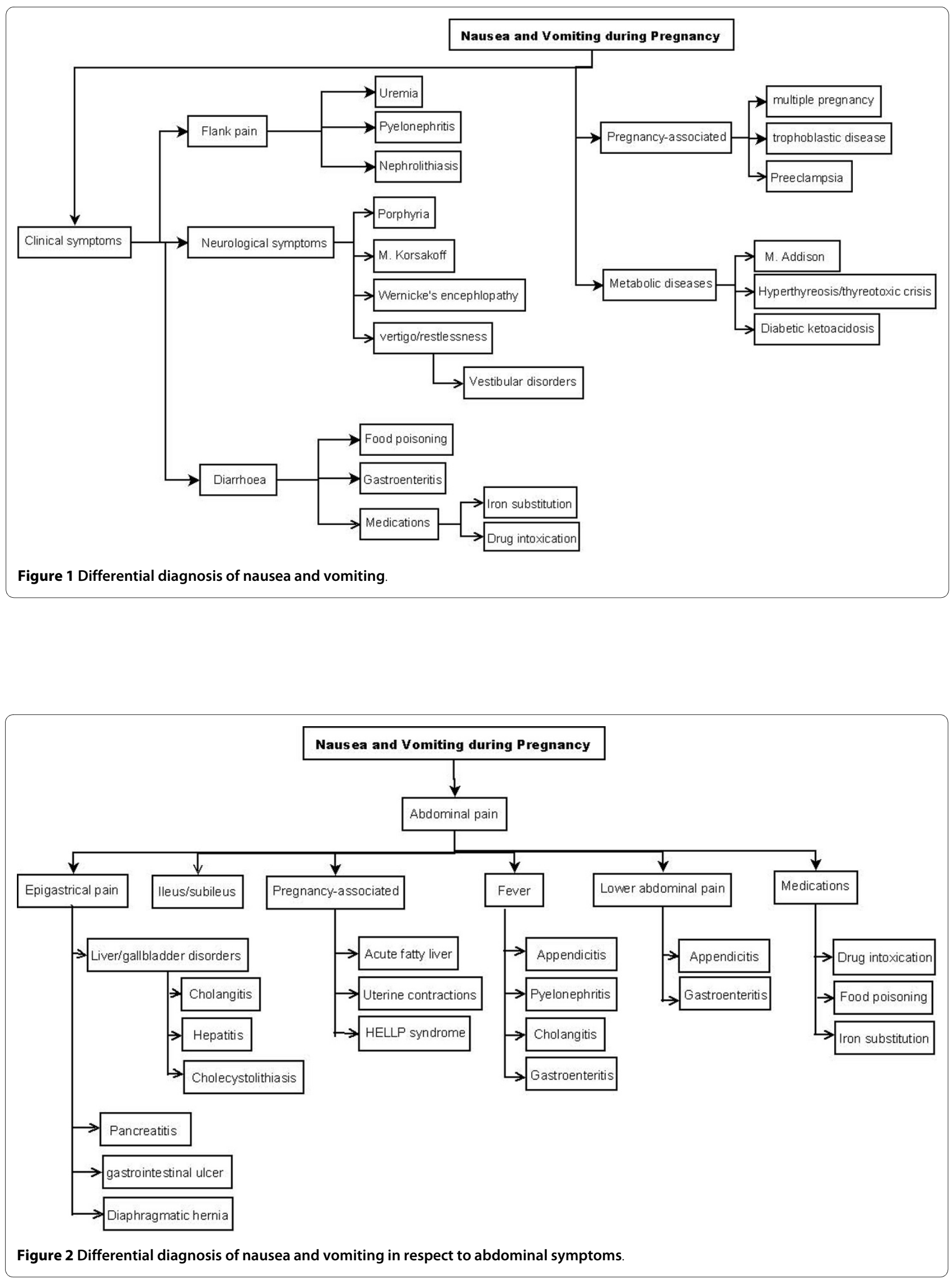
(ii) grade 2, pronounced feelings of sickness with metabolic imbalance [2].

In this article the aetiology, diagnosis, clinical presentation and treatment options will be outlined on the basis of a selective literature review.

\section{Aetiology}

The aetiology of NVP and hyperemesis in pregnancy is unknown, although some biological, physiological and psychological as well as sociocultural factors are thought to be contributory factors [8]. According to another theory, nausea and vomiting during pregnancy might be an evolutionary adaptation that prevents the intake of potentially noxious food. Such harmful substances may be pathogenic microorganisms in meat and toxins in strong-tasting vegetables and beverages. Thus, by avoiding the ingestion of those toxic components, it is supposed that the embryo is protected from miscarriage. Interviews on more than 5400 pregnant women obtained from 20 studies of gestational aversions, as well as enquiries on more than 6200 pregnant women obtained from 21 studies of gestational cravings, show that most women during pregnancy prefer food categories that are less likely to contain toxic substances [9]. However, severe forms of NVP (such as HG) always require medical intervention.

Risk factors for HG include multiple pregnancy, nulliparity, obesity, metabolic disturbances, a history of HG in a previous pregnancy, trophoblastic disorders, psychological disorders (for example, eating disorders such as anorexia nervosa or bulimia) and a history of migration [10-12].

\section{Human chorionic gonadotrophin (HCG)}

HCG is the most likely endocrine factor which accounts for the development of HG. This conclusion is based on observed associations between increased production of HCG (as in molar or in multiple pregnancies) [13-15] and the fact that the incidence of hyperemesis is highest at the time when HCG production reaches its peak during pregnancy (around 9 weeks gestation) [13]. However, there is no evidence to support this hypothesis and some pregnant women do not experience nausea and vomiting despite elevated HCG-levels. In addition, patients suffering from chorionic carcinoma - a disease that is also associated with an increase in HCG - do not usually experience vomiting. These controversial findings may be caused by the varying biological activity of different isoforms of HCG as well as an individual sensitivity for emetogenic stimuli. Additionally, hormone-receptor interactions may modify the effects of HCG leading to hyperemesis in some cases but having no emetic consequences in others [5].

\section{Helicobacter pylori infection}

Chronic infection with helicobacter pylori may also cause HG [16-22]. The histological examination of the gastric mucosa in a total of 30 women (20 HG patients and 10 pregnant volunteers) showed that the bacterium was present in almost $95 \%$ of patients with hyperemesis but in only $50 \%$ of controls. The differences between the two groups were statistically significant $(P=0.009)$ [16]. In a metaanalysis of 14 case-control studies, which included a total of 1732 patients and controls, an association between the presence of helicobacter pylori and HG was suggested, although not all of the analysed studies reached statistical significance [odds ratio from 0.55 to 109.33, confidence interval (CI) 95\%] [6]. Nevertheless, in one study examining both saliva $(61.8 \%$ detection of helicobacter pylori in patients with HG versus $27.6 \%$ in symptom-free pregnant women) and serum $(52.9 \%$ versus $20.7 \%)$ for the bacterium results were significant $(P<$ 0.0001 , CI 95\%) [17], as were cytotoxin-associated gene A and serum findings in a Chinese study [19]. Two observational studies of five patients with HG reported no improvement in symptoms in response to standard drug treatment. However, a marked response was seen following antibiotic treatment (erythromycin) for helicobacter pylori $[18,22]$. Therefore, although a helicobacter pylori infection might not be the only cause of HG, it should be taken into consideration as a contributing factor in intractable cases of this condition.

\section{Hormonal factors}

Several hormones may cause hyperemesis. These are oestrogen, progesterone, adrenocorticotropic hormone $(\mathrm{ACTH})$, cortisol, growth hormone and prolactin. Evidence for the involvement of serotonin in chemotherapyinduced nausea and vomiting was found some years ago $[23,24]$ implying that this hormone might also play an important role in HG but findings have been inconsistent: In a prospective study on a total of 33 women (13 patients suffering from hyperemesis, 10 healthy pregnant women and 10 nongravid women) serotonin levels were evaluated. The results showed no differences between the three groups [25].

\section{Progesterone}

Lower [12] and elevated [26] progesterone levels have been reported in patients with hyperemesis. These alterations are caused by pregnancy-associated changes in the mother's immune system: In a prospective study on 44 pregnant women (22 patients with hyperemesis and 22 matching healthy pregnant women) a significant increase in plasma progesterone levels was shown in women with hyperemesis compared to women without the condition $(P<0.05)$. A potentially emetogenic elevation of HCG due to these modifications is proposed [12]. Lower pro- 
gesterone levels were found in a prospectively controlled study with 62 NVP subjects versus 40 nonaffected pregnant women $(P<0.02)[12]$. However, several other studies found no association between serum progesterone concentration and hyperemesis [14,27]. Progesterone may cause reduced gastrointestinal motility during pregnancy [28]. Gastric dysrhythmias (tachygastria, bradygastria) may also occur [29], thus contributing to hyperemesis.

\section{Oestrogens}

Increased levels of oestrogen and oestradiol are known to cause nausea and vomiting in pregnancy [30]. Hence, the presence of a female foetus is associated with severe nausea and vomiting [31,32] usually explained by a raised concentration of oestrogen in utero [31]. This is consistent with the observation that oestrogen treatment can cause nausea. It has been suggested that patients with hyperemesis are probably more sensitive to oestrogen effects than asymptomatic pregnant women [12]. Cigarette smokers usually show lower levels of both oestrogens and HCG. Consistently, HG occurs less often in women who smoke $[33,34]$. However, some studies have reported negative results regarding the association between elevated oestrogen levels and the development of hyperemesis [35].

\section{Hyperthyroidism}

Thyroid function is physiologically altered during pregnancy, including stimulation by HCG [36]. Hyperthyroidism with normal fT3 and fT4 levels, but decreased levels of thyroid stimulating hormone (TSH), may also be implicated in HG $[37,38]$. A self-limiting, transient hyperthyroidism of hyperemesis gravidarum (THHG) has been proposed according to the findings of a screening series in 1900 pregnant women who showed markedly increased HCG and fT4 levels [36]. THHG may persist until 18 weeks gestation and does not require treatment. This condition may be partly caused by the high levels of HCG that are often seen in patients with HG since HCG and TSH have a very similar protein structure, thus enabling HCG to act like TRH and hyper-stimulate the thyroid, which recently has been shown conclusively $[39,40]$.

Assignment of a diagnosis of THHG requires the following [2]:

- pathological serology results during hyperemesis

- a negative history of hyperthyroidism before the pregnancy

- the absence of thyroid antibodies

\section{Psychosomatic approach}

Several years ago the theory of underlying psychological alterations as main causative factor for HG was proposed [41]. This was partly thought to be due to a lack of evi- dence of any straight biological pathophysiological pathway [42], partly due to the finding that many patients seem to need psychological help to cope with the condition.

Not only is their physical identity profoundly changed by the pregnancy but also their daily social life. One former commonly used explication for development of $\mathrm{HG}$ was a psychiatric explanation of vomiting as a subconscious wish for an abortion or - in a different approach - a conversion disorder underlying the condition [43].

Although this might be the cause in individual cases, nowadays the generally accepted opinion is that severe psychological afflictions are a consequence of constant vomiting rather than the source of it $[8,13]$. Such a psychiatric sequel may continue even postpartum [10]. Perhaps as a reaction to the psychological strain of the patients, during the last years psychological treatment approaches seem to increase to a varying extent in different countries [44].

Davis et al. found no differences in the incidence of HG in association with marital status, whether or not the pregnancy was desired, or the patient's attitude towards the pregnancy [45]. The most frequently cited study used the psychological Cornell Medical Index to assess 44 pregnant women with, and 49 pregnant women without, HG [35]. A further study used the MMPI to assess patients with HG [46]. Both studies showed that women with hyperemesis had an excessive emotional bond to their mothers and that the main types of personality were hysterical and infantile. Additionally, a systematic questionnaire based on interviews with 23 hospitalized women with HG showed suppressed ambivalent feelings of the expectant mothers towards their pregnancies that were expressed in severe vomiting [47], but this association has not been proven to a sufficient extent [42]. Based on a case control study in more than 11,000 pregnant women an association between pre-pregnancy diagnosed psychiatric conditions (for example, depression, anxiety or drug abuse) and HG was seen $(P<0.001)$ [48]. However, these studies have to be evaluated critically because of a potential methodological weakness [42].

More recent approaches assume that neither a merely physical pathway nor a completely psychological pathomechanism can cause such a complex disease but on the contrary $\mathrm{HG}$ is a multifactorial condition. Focusing entirely on psychogenic factors raises the risk that patients are not taken seriously in their suffering and probably not all existing therapeutic options are used. However, neglecting the psychosomatic aspects in the development and course of HG in some patients harbours the risk of treating only the symptoms of the condition without eliminating the cause. 


\section{Medical history and clinical presentation}

Clinical symptoms are usually non-specific and it is important to exclude the more unusual causes of nausea and vomiting. These include peptic ulceration, hepatitis, pancreatitis, thyroid disease, gastrointestinal obstruction and adrenocortical insufficiency (see Table 1) [13]. An onset of symptoms after 10 weeks gestation is atypical for NVP and systematic exclusion of the diseases mentioned above is particularly important in such cases.

NVP usually has very few attendant symptoms other than fatigue, exhaustion and indisposition. Pyrexia, gastric pain, headache or neurologic signs point to other causes, although the latter finding may, in rare cases, result from severe and prolonged NVP (for example, Wernicke's encephalopathy or central pontine myelinolysis). In the case of elevated thyroid hormones, it is important to distinguish between THHG and primary thyroid disease. Furthermore, chronic underlying conditions that may have been exacerbated or unmasked by the pregnancy should be excluded [5].

Metabolic ketoacidosis and ketonaemia (acetone-like breath) may also occur with occasional pyrexia and hepatic symptoms (for example, jaundice). In some cases, drowsiness and intellectual slowness are present and this may lead to delirium. Laboratory investigations should include haematocrit, electrolytes, transaminases, bilirubin and thyroid function tests as well as urinary status (presence or absence of ketone bodies, specific weight, $\mathrm{pH})$. In addition, ultrasonography should be performed in order to exclude multiple pregnancy, trophoblastic disorders and neoplasias. If a psychic component of the disorder is suspected, ultrasound scans should not be repeated too often as this may aggravate psychosomatic symptoms [49].

In order to diagnose underlying psychological factors, a psychosomatic dialogue aiming at the formation of a working alliance between patient and physician is essential [50]. This often reveals a stressful and intolerable situation in the patient's social environment that she is unable to escape from or avoid. This psychosocial distress is then converted into a somatic symptom [51]. In the case of persistent vomiting or conspicuous symptoms the psychological differential diagnosis should include deep and defended psychic conflicts [2].

\section{Treatment strategies}

Treatment strategies for HG should be based on the severity of symptoms and multimodal in nature (advice, hydration, medication, hospitalization and psychosomatic counselling when necessary; see Figure 3). The severity of the condition can be assessed by numerous questionnaires. Two of the most widely used questionnaires are the Pregnancy-Unique Quantification of Eme-
Table 1: Diseases associated with nausea and vomiting during pregnancy (alphabetical order), adapted from reference.

\begin{tabular}{ll}
\hline Causes & Differential diagnosis \\
\hline Gastrointestinal causes & Appendicitis \\
& Diaphragmatic hernia \\
& Gastroenteritis
\end{tabular}

Hepatic or cholecystic disorders

Hepatitis

Ileus and subileus

Pancreatitis

Stomach cancer

Stomach ulcer or duodenal ulcer

Metabolic causes

Addison's disease

Diabetic ketoacidosis

Hyperthyroidism

Porphyria

Thyrotoxicosis

Neurological causes Korsakoff's psychosis

Migraine

Vestibular disorders

Wernicke's encephalopathy

Pregnancy associated

Acute fatty liver

Emesis gravidarum ( $<5 \times /$ day $)$

Hyperemesis gravidarum $(>5 \times /$ day $)$

Multiple pregancy 


\section{Table 1: Diseases associated with nausea and vomiting during pregnancy (alphabetical order), adapted from reference . (Continued)}

\begin{tabular}{|c|c|}
\hline & Pre-eclampsia \\
\hline & Premature contractions \\
\hline \multirow[t]{4}{*}{ Urogenital causes } & Degenerative uterine fibroids \\
\hline & Nephrolithiasis \\
\hline & Pyelonephritis \\
\hline & Uremia \\
\hline \multirow[t]{3}{*}{ Other causes } & Drug poisoning \\
\hline & Food poisoning \\
\hline & Iron medication \\
\hline
\end{tabular}

sis and Nausea (PUQE) scoring index, which assesses nausea and vomiting over $12 \mathrm{~h}$, and the PUQE-24, an extension of the original PUQE, which assesses symptoms over $24 \mathrm{~h}[52,53]$. Another recently developed score is the Hyperemesis Impact of Symptoms Questionnaire (HIS) that brings into focus not only physical but also psychosocial factors in order to assess the impact of HG holistically [54].

\section{Initial management}

For initial management, dietary and lifestyle advice is often sufficient to ameliorate symptoms and improve quality of life. Mild forms of nausea and vomiting can usually be managed by following general nutritional advice such as the intake of small amounts of fluids and food throughout the day rather than eating fewer but larger meals. Foods should be rich on carbohydrates and low in fat and acid [2]. Light snacks, nuts, dairy products, beans and dry and salty biscuits are also frequently recommended. Additionally, electrolyte-replacement drinks and oral nutritional supplements are advisable for ensuring maintenance of electrolyte balance and an adequate intake of calories. Protein-predominant meals have a positive effect because they are eupeptic and are able to reduce nausea more effectively than equicaloric carbohydrate and fat meals or noncaloric meals [55]. If the smell of hot food triggers nausea, cold food should be prepared instead. Lifestyle advice may include avoiding stress and resting in the event of incipient nausea.

Emotional support and, if needed, psychosomatic care administered by a psychologist or a medical doctor with training in psychosomatics can be helpful. Depending on the severity of the symptoms, supportive counselling or crisis intervention might be required [2].

\section{Medication}

If symptoms cannot be managed by dietary and lifestyle changes alone, low dose antiemetics may be administered. All pharmacologic interventions should be based upon known safety, proven efficacy and cost effectiveness [56].

In a metaanalysis of 28 randomized trials of medications for the treatment of HG, antiemetics diminished nausea in early pregnancy and were superior to placebo [2]. Ondansetron is one of the more commonly used and effective drugs and has relatively few side effects $[13,57,58]$.

Other recommended options are the use of metoclopramide to improve gastrointestinal motility and administration of pyridoxine (vitamin B6) [59]. Pyridoxine is given three times daily at a dose of $10-25 \mathrm{mg}$ starting with a low dose that may reduce symptoms and has been proven to be more effective than placebo $[13,60]$. The daily dose can be increased up to $200 \mathrm{mg}$ without side effects $[61,62]$. However, a more recent placebo-controlled trial demonstrated that a combination of oral pyridoxine and metoclopramide did not improve the vomiting frequency or the nausea score [63].

Antihistamines and anticholinergics such as meclizine, dimenhydrinate and diphenhydramine have also been shown to be superior to placebo and can be used safely for the treatment of nausea and vomiting in pregnancy (see Table 2) [64].

However, the side effect profiles vary between the different medications: While nearly all of the above mentioned medicaments may cause dizziness, drowsiness, constipation or dry mouth, more severe adverse effects comprise convulsions, decreased alertness, heartbeat alterations and hallucinations (doxylamine, metoclopramide, diphenhydramine, dimenhydrinate, promethazine). Headache, muscle pain or tremor and fever (prednisolone, procholrperazine, promethazine, dimenhydrinate, doxylamine, metoclopramide) may also occur.

Interestingly, diazepam also has positive effects on HG, probably due to its sedative properties [65]. A prospective randomized clinical trial in 74 patients showed that a combination of antiemetic therapy and diazepam reduced the need for hospitalization and improved patient satisfaction [56]. Frequent use of diazepam, however, might lead to dependency. Another risk factor that must be taken into consideration is the possibility of fetal side effects $[2,66]$. Antidepressants such as mirtazapine have also been used with some success in ameliorating the symptoms of HG [67]. 


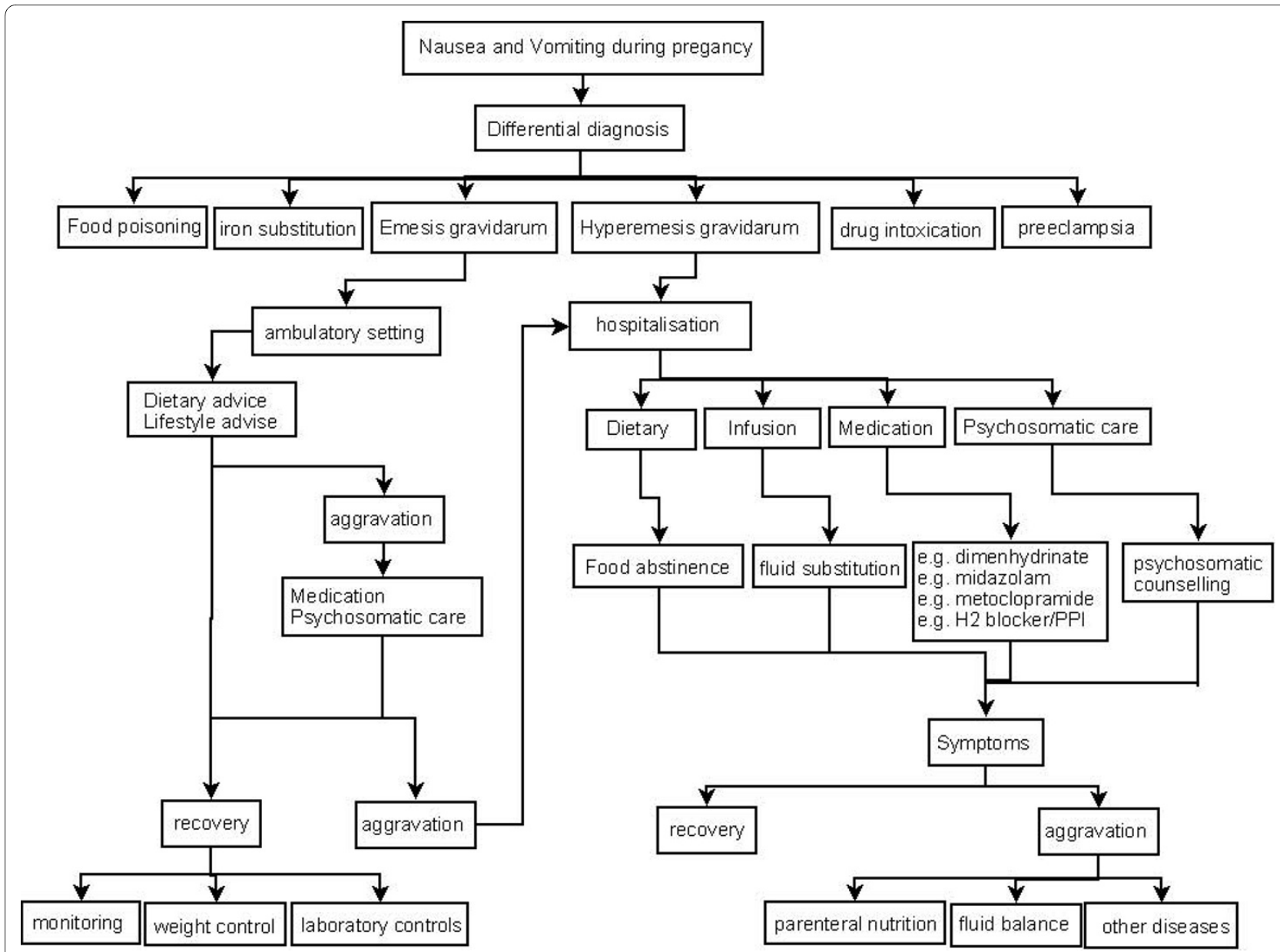

Figure 3 Multimodal character of treatment strategies in hyperemesis gravidarum, adapted from reference [2].

\section{Non-pharmacological interventions}

Alternative treatments include acupressure, especially on the P6 point (Neiguan) on the inside of the wrist $[68,69]$. However, despite several trials, there is still minimal experimental evidence that acupuncture is effective in relieving the symptoms of HG., A supplement that may be helpful is ginger. In a trial of 66 women ginger $(1 \mathrm{~g} /$ day) compared to placebo was shown to be of benefit for those suffering from both nausea and vomiting [70]. Another prospective study of 187 pregnant women with symptoms of NVP showed that ginger had a mild effect in ameliorating nausea and vomiting without negative effects on the fetus [71]. Available data show that ginger has no apparent teratogenic potential and can be used safely up to a daily dose of 1 gram [5,62,72-75].

\section{Hospitalization}

In patients with more severe dehydration or ketonuria, inpatient admission is required (see Figure 3). Sometimes hospitalization alone is sufficient to improve symptoms ('holding function') because it may provide psychological relief. However, the treatment of dehydration is considered to be of paramount importance [13].

The primary therapeutic step is total food withdrawal. Maintaining hydration or, in the case of severe dehydration achieving quick and sufficient rehydration, is the most important intervention. Volume and electrolyte replacement (at least $3 \mathrm{~L} /$ day), correction of potential electrolyte imbalance, administration of vitamins and parenteral administration of carbohydrate and amino acid solutions (about 8400 to $10,500 \mathrm{~kJ} / \mathrm{d}$ ) are recommended (see Table 3). Rehydration is most easily and quickly accomplished intravenously and this reduces adverse symptoms very effectively.

Although peripheral catheters are considered to be advantageous, a study of 94 patients with HG reported the occurrence of a substantial number of complications in association with peripherally inserted central catheters (PICC lines) compared to treatment with medication only. This suggests that invasive treatment options should be thoroughly investigated before being introduced [76]. Major complications associated with PICC lines are 
Table 2: Antiemetic agents and supposed dosage in hyperemesis gravidarum, adapted from references

\begin{tabular}{|c|c|c|c|}
\hline $\begin{array}{c}\text { Food and Drug } \\
\text { Admnistration category }\end{array}$ & Medication & Administration & Suggested dosage \\
\hline \multirow[t]{2}{*}{ A } & Pyridoxine (vitamin B6) & Oral & 20 mg $3 \times$ per day (max. dose: 200 mg per day) \\
\hline & Doxylamine & Oral & $\begin{array}{l}25 \mathrm{mg} \text { at night and } 12.5 \mathrm{mg} \text { in the morning } \\
\text { accompanied by } 10 \mathrm{mg} \text { of pyridoxine (maximum } \\
\text { dose: } 80 \mathrm{mg} \text { per day) }\end{array}$ \\
\hline \multirow[t]{5}{*}{ B } & Ondansetron & Oral/intravenously (IV) & $\begin{array}{l}\text { 4-8 mg 2-3 } \times \text { per day/2-4 mg every } 6-8 \text { h or } 8 \text { mg every } \\
12 \text { h IV }\end{array}$ \\
\hline & Metoclopramide & Oral & $5-10 \mathrm{mg} 3-4 \times$ per day \\
\hline & Meclizine & Oral/rectal & $25-100 \mathrm{mg} 2-4 \times$ per day $/ 1 \times$ per day \\
\hline & Diphenhydramine & Oral/IV & $25-50 \mathrm{mg}$ every $6-8 \mathrm{~h}$ \\
\hline & Dimenhydrinate & Oral/IV/rectal & $50 \mathrm{mg} 3-4 \times$ per day $/ 62 \mathrm{mg} 2 \times$ per day $/ 1-3 \times$ per day \\
\hline \multirow[t]{3}{*}{ C } & Promethazine & Oral/IV & $12.5-25 \mathrm{mg}$ up to $6 \times$ per day \\
\hline & Prochlorperazine & Rectal & $25 \mathrm{mg}$ per day or $2 \times$ per day \\
\hline & Prednisolone & Oral & $40-60 \mathrm{mg}$ per day reducing by half every 3 days \\
\hline- & Ginger & $\begin{array}{l}\text { Oral (biscuits, confectionary, } \\
\text { crystals, powder, tablets, } \\
\text { capsules, fresh ginger) }\end{array}$ & Up to $1 \mathrm{~g}$ per day in divided doses \\
\hline
\end{tabular}

infections and thrombosis or endocarditis. In a retrospective study of 85 pregnant women with central catheters, $25 \%$ developed serious complications including infections (12\%) [77]. To date, no fetal or maternal medical benefit has been found for PICC lines in comparison to serial peripheral catheters and the use of central catheters is only recommended in exceptional cases [78].

An alternative to parenteral nutrition may be nasogastric feeding tubes because, in cases of intractable nausea and vomiting, they seem to relieve symptoms and provide adequate nutritional support [79]. Another advantage of enteral feeding via nasogastric tubes in comparison to parenteral nutrition is that enteral feeding is more cost effective [80]. In order to determine whether an underlying helicobacter pylori infection is (partially) causative, helicobacter pylori testing may be performed. In the event of a positive result, $\mathrm{H} 2$ blockers (for example, cimetidine) or proton pump inhibitors (for example, omeprazol) can be added to infusions [20,81-83].

If hyperemesis is refractory to treatment, corticoids (for example, hydrocortisone) may also be used [84]. Corti- costeroids are considered to be safe and have no known adverse effects for the fetus. IV administration may be preferable to oral administration, particularly in refractory cases, as the effect is greater and more rapid [84]

Total parenteral nutrition (TPN) may be useful in highly refractory cases in order to ensure a sufficient calorie intake [85]. However, there is no evidence to support the use of TPN and it should only be used as a last resort when all other treatments have failed, as it can be associated with severe complications such as thrombosis, metabolic disturbances and infection [86].

In patients with persistent symptoms, other disorders should be excluded (see Figures 1 and 2). Treatment should be continued until vomiting ceases or occurs less than three times a day. Subsequent food reintroduction should be carried out gradually [2].

\section{Psychosomatic therapeutic options}

Psychosomatic therapies involve dialogues between the physician and the pregnant woman to evaluate the psychosocial situation in her marital relationship, activate 
Table 3: Recommended procedure for substitution of vitamins during total parenteral nutrition (personal communication Ramsauer and Vetter, Berlin, Germany).

Parenteral nutrition via peripheral venous access

\begin{tabular}{lll}
\hline Main infusion & Adjuvants (daily dose) & Speed of operation \\
\hline $500 \mathrm{~mL}$ glucose-infusion 5\% & & $50 \mathrm{~mL} / \mathrm{h}$ \\
& $\cdot 200 \mathrm{mg}$ vitamin B1 (thiaminchloride), \\
$\cdot 200 \mathrm{mg}$ vitamin B6 (pyridoxine), & $\cdot 200 \mu \mathrm{g}$ vitamin B12 (cyanocobalamine), \\
$\cdot$ & \\
& \\
\hline
\end{tabular}

Parenteral nutrition via central venous access

\begin{tabular}{lll}
\hline Main infusion & Adjuvants (daily dose) & Speed of operation \\
\hline $500 \mathrm{~mL}$ glucose-infusion $40 \%$ & $\cdot 200 \mathrm{mg}$ vitamin B1(thiaminchloride), \\
& $\cdot 200 \mathrm{mg}$ vitamin B6 (pyridoxine), \\
$\cdot 200 \mu \mathrm{g}$ vitamin B12 (cyanocobalamine), & $50 \mathrm{~mL} / \mathrm{h}$ \\
$\cdot$ & $2000 \mathrm{mg}$ vitamin C (ascorbic acid) \\
\hline
\end{tabular}

individual resources and provide support regarding acceptance of the pregnancy. On the basis of anamnestic data, other proper therapeutic options such as hypnotherapy, psychotherapy or behavioural therapy may be considered. In approximately $90 \%$ of all women hospitalized for HG, symptoms ameliorate without any further therapeutic intervention. This may be due to inpatient nursing support and relief from overstraining, as well as to being removed from the conflict-causing environment. Nevertheless, consideration of psychosocial factors while making the diagnosis may improve long-term treatment outcome [87].

\section{Pregnancy outcome and prognosis}

In most cases, nausea and vomiting during pregnancy is self limiting and is usually resolved by around 20 weeks gestation [13]. Interestingly, it is consistently associated with lower rates of miscarriage, retarded intrauterine growth and preterm delivery and fetal outcomes are, in most cases, excellent [11,88-90].

Other causes of severe distress in these patients include loss of time from work and a reduced quality of life [1]. An investigation of 147 patients evaluated the impact of NVP on family, social and occupational functioning as well as quality of life. It found that $82.8 \%$ of patients were limited in their usual daily activities, not only by the presence of constant nausea and frequent vomiting, but also by the psychological burden of not feeling well for several weeks or months [91]. Another stressful aspect of the disorder is the change of the patient's role within her social or occupational environment: Many women feel helpless and incapable and misunderstood by their relatives. Family problems range from neglect of the household to neg- ative alterations in the relationship between the pregnant woman and her spouse. Social functioning is often affected, with a reduction in social commitments, partly due to feelings of embarrassment. Most patients with severe NVP or HG miss at least a few weeks of their paid employment and report that they are less attentive to their work [91].

NVP and HG may cause considerable direct (for example, medication) and indirect (for example, loss of productivity) costs, which can amount to hundreds of dollars. These costs apply not only to the patients, but also to society and the health care system [92]. More serious medical complications include the Mallory-Weiss syndrome (acute increase in oesophageal pressure due to vomiting) and oesophageal rupture (due to severe vomiting), pneumothorax, peripheral neuropathy, coagulopathy, Wernicke's encephalopathy (due to lack of thiamine), pre-eclampsia and fetal growth retardation [11,13,93-95].

The psychosomatic aspects of hyperemesis should also be considered. Interestingly, psychosocial morbidity for the mother often presents in the form of secondary depression, which affects up to $7 \%$ of patients with HG $[10,96]$. Therefore, adequate assessment, observation, and treatment of a possible psychosomatic disorder should also be considered.

\section{Conclusions}

Since the causal factors of HG are multifarious, treatment of this condition should be multimodal, ranging from dietary and lifestyle advice to psychosomatic counselling or psychoanalytic therapy. Administration of antiemetic drugs may be necessary, as well as IV fluid replacement, food administration via nasogastric or parenteral routes 
in severe cases. Since this condition is accompanied by a significant reduction in quality of life for the patient and high costs to the healthcare system, general practitioners and obstetricians should ensure that they are well informed about this condition [97] so that they are able to provide advice, counselling and effective medication to pregnant women and thus prevent the exacerbation of symptoms.

\begin{abstract}
Abbreviations
ACTH: adrenocorticotropic hormone; HCG: human chorionic gonadotrophin HG: hyperemesis gravidarum; IV: intravenous; MMPI: Minnesota Multiphasic Personality Inventory; NVP: nausea and vomiting during pregnancy; PICC: peripherally inserted central catheter; PUQE: Pregnancy-Unique Quantification of Emesis and Nausea; THHG: hyperthyroidism of HG; TPN: total parenteral nutrition; TSH: thyroid stimulating hormone.
\end{abstract}

\section{Competing interests}

The authors declare that they have no competing interests.

\section{Authors' contributions}

$\mathrm{JJ}$ and IM designed, conducted the literature review and drafted most of the manuscript. RK wrote the psychosomatic part of this article. All authors read and approved the final manuscript.

\section{Acknowledgements}

The authors would like to thank Cornelia Lundell for her very helpful revision of the orthographic aspects of the manuscript.

\section{Author Details}

First Department of Obstetrics and Gynaecology, Campus Innenstadt, LudwigMaximilians-University, Maistrasse 11, 80337 Munich, Germany

Received: 10 February 2010 Accepted: 15 July 2010

Published: 15 July 2010

\section{References}

1. Gadsby R, Barnie-Adshead AM, Jagger C: A prospective study of nausea and vomiting during pregnancy. Br J Gen Pract 1993, 43:245-248.

2. Mylonas I, Gingelmaier A, Kainer F: Nausea and vomiting in pregnancy. Dtsch Arztebl 2007, 104:A1821-1826.

3. Klebanoff MA, Koslowe PA, Kaslow R, Rhoads GG: Epidemiology of vomiting in early pregnancy. Obstet Gynecol 1985, 66(5):612-616.

4. Rodien P, Bremont C, Sanson ML, Parma J, Van Sande J, Costagliola S, Luton JP, Vassart G, Duprez L: Familial gestational hyperthyroidism caused by a mutant thyrotropin receptor hypersensitive to human chorionic gonadotropin. N Engl J Med 1998, 339:1823-1826.

5. ACOG (American College of Obstetrics and Gynecology): Practice bulletin: nausea and vomiting of pregnancy. Obstet Gynecol 2004, 103(4):803-814

6. Golberg D, Szilagyi A, Graves L: Hyperemesis gravidarum and Helicobacter pylori infection: a systematic review. Obstet Gynecol 2007 110:695-703.

7. Gadsby R, Barnie-Adshead AM, Jaggerc C: Pregnancy nausea related to women's obstetric and personal histories. Gynecol Obstet Invest 1997, 43:108-111

8. Simpson SW, Goodwin TM, Robins SB, Rizzo AA, Howes RA, Buckwalter DK, Buckwalter JG: Psychological factors and hyperemesis gravidarum. J Womens Health Gend Based Med 2001, 10:471-477.

9. Sherman PW, Flaxman SM: Nausea and vomiting of pregnancy in an evolutionary perspective. Am J Obstet Gynecol 2002, 186:S190-7.

10. Poursharif B, Korst LM, Fejzo MS, MacGibbon KW, Romero R, Goodwin TM: The psychosocial burden of hyperemesis gravidarum. J Perinato/ 2008, 28:176-181

11. Broussard CN, Richter JE: Nausea and vomiting of pregnancy. Gastroenterol Clin North Am 1998, 27:123-151.

12. Jarnfelt-Samsioe A: Nausea and vomiting in pregnancy: a review. Obstet Gynecol Surv 1987, 42:422-427.
13. Sheehan $P$ : Hyperemesis gravidarum--assessment and management. Aust Fam Physician 2007, 36:698-701.

14. Masson GM, Anthony F, Chau E: Serum chorionic gonadotrophin (hCG), schwangerschaftsprotein 1 (SP1), progesterone and oestradiol levels in patients with nausea and vomiting in early pregnancy. Br J Obstet Gynaecol 1985, 92:211-215.

15. Goodwin TM, Hershman JM, Cole L: Increased concentration of the free beta-subunit of human chorionic gonadotropin in hyperemesis gravidarum. Acta Obstet Gynecol Scand 1994, 73:770-772.

16. Bagis T, Gumurdulu Y, Kayaselcuk F, Yilmaz ES, Killicadag E, Tarim E: Endoscopy in hyperemesis gravidarum and Helicobacter pylori infection. Int J Gynaecol Obstet 2002, 79:105-109.

17. Hayakawa S, Nakajima N, Karasaki-Suzuki M, Yoshinaga H, Arakawa Y, Satoh K, Yamamoto T: Frequent presence of Helicobacter pylori genome in the saliva of patients with hyperemesis gravidarum. Am J Perinatol 2000, 17:243-247.

18. Jacoby EB, Porter KB: Helicobacter pylori infection and persistent hyperemesis gravidarum. Am J Perinatol 1999, 16:85-88.

19. Xia LB, Yang J, Li AB, Tang SH, Xie QZ, Cheng D: Relationship between hyperemesis gravidarum and Helicobacter pylori seropositivity. Chin Med J (Engl) 2004, 117:301-302.

20. Sandven I, Abdelnoor M, Nesheim BI, Melby KK: Helicobacter pylori infection and hyperemesis gravidarum: a systematic review and metaanalysis of case-control studies. Acta Obstet Gynecol Scand 2009, 88:1190-1200

21. Kazerooni T, Taallom M, Ghaderi AA: Helicobacter pylori seropositivity in patients with hyperemesis gravidarum. Int I Gynaecol Obstet 2002, 79:217-220.

22. El Younis CM, Abulafia O, Sherer DM: Rapid marked response of severe hyperemesis gravidarum to oral erythromycin. Am J Perinatol 1998, 15:533-534

23. Cubeddu LX, Hoffmann IS, Fuenmayor NT, Finn AL: Efficacy of ondansetron (GR 38032F) and the role of serotonin in cisplatininduced nausea and vomiting. N Engl J Med 1990, 322:810-816.

24. Wilder-Smith OH, Borgeat A, Chappuis P, Fathi M, Forni M: Urinary serotonin metabolite excretion during cisplatin chemotherapy. Cancer 1993, 72:2239-2241

25. Borgeat $A$, Fathi $M$, Valiton A: Hyperemesis gravidarum: is serotonin implicated? Am J Obstet Gynecol 1997, 176:476-477.

26. Yoneyama Y, Suzuki S, Sawa R, Yoneyama K, Doi D, Otsubo Y, Araki T: The T-helper 1/T-helper 2 balance in peripheral blood of women with hyperemesis gravidarum. Am J Obstet Gynecol 2002, 187:1631-1635.

27. Lagiou P, Tamimi R, Mucci LA, Trichopoulos D, Adami HO, Hsieh CC: Nausea and vomiting in pregnancy in relation to prolactin, estrogens, and progesterone: a prospective study. Obstet Gynecol 2003, 101:639-644.

28. Koch KL, Frissora CL: Nausea and vomiting during pregnancy. Gastroenterol Clin North Am 2003, 32:201-234. vi

29. Walsh JW, Hasler WL, Nugent CE, Owyang C: Progesterone and estrogen are potential mediators of gastric slow-wave dysrhythmias in nausea of pregnancy. Am J Physiol 1996, 270:G506-514.

30. Depue RH, Bernstein L, Ross RK, Judd HL, Henderson BE: Hyperemesis gravidarum in relation to estradiol levels, pregnancy outcome, and other maternal factors: a seroepidemiologic study. Am J Obstet Gynecol 1987, 156:1137-1141.

31. Schiff MA, Reed SD, Daling JR: The sex ratio of pregnancies complicated by hospitalisation for hyperemesis gravidarum. BJOG 2004, 111:27-30.

32. James $\mathrm{WH}$ : The associated offspring sex ratios and cause(s) of hyperemesis gravidarum. Acta Obstet Gynecol Scand 2001, 80:378-379.

33. Bernstein L, Pike MC, Lobo RA, Depue RH, Ross RK, Henderson BE: Cigarette smoking in pregnancy results in marked decrease in maternal hCG and oestradiol levels. Br J Obstet Gynaecol 1989, 96:92-96.

34. Baron JA, La Vecchia C, Levi F: The antiestrogenic effect of cigarette smoking in women. Am J Obstet Gynecol 1990, 162:502-514.

35. Fairweather DV: Nausea and vomiting during pregnancy. Obstet Gynecol Annu 1978, 7:91-105.

36. Glinoer D: The regulation of thyroid function in pregnancy: pathways of endocrine adaptation from physiology to pathology. Endocr Rev 1997, 18:404-33.

37. Chan NN: Thyroid function in hyperemesis gravidarum. Lancet 1999 353:2243 
38. Blankenstein TJ, Kainer F, Friese K, Mylonas I: Extended hyperemesis gravidarum in a patient after total thyroidectomy. Arch Gynecol Obstet 2009, 280:1029-1031.

39. Rodien P, Jordan N, Lefèvre A, Royer J, Vasseur C, Savagner F, Bourdelot A, Rohmer $\mathrm{V}$ : Abnormal stimulation of the thyrotrophin receptor during gestation. Hum Reprod Update 2004, 10(2):95-105.

40. Yoshimura M, Hershman JM: Thyrotropic action of human chorionic gonadotropin. Thyroid 1995, 5(5):425-34.

41. Buckwalter JG, Simpson SW: Psychological factors in the etiology and treatment of severe nausea and vomiting in pregnancy. Am J Obstet Gynecol 2002, 186:S210-214

42. Munch S: Chicken or the egg? The biological-psychological controversy surrounding hyperemesis gravidarum. Soc Sci Med 2002, 55:1267-1278.

43. El-Mallakh RS, Liebowitz NR, Hale MS: Hyperemesis gravidarum as conversion disorder. J Nerv Ment Dis 1990, 178:655-659.

44. Goodwin TM, Poursharif B, Korst LM, MacGibbon KW, Romero R, Fejzo MS: Secular trends in the treatment of hyperemesis gravidarum. Am J Perinatol 2008, 25:141-147.

45. Davis M: Nausea and vomiting of pregnancy: an evidence-based review. J Perinat Neonatal Nurs 2004, 18:312-328.

46. Fairweather DV: Nausea and vomiting in pregnancy. Am J Obstet Gynecol 1968, 102:135-175.

47. Karpel L, de Gmeline C: Psychological approach to hyperemis gravidarum. J Gynecol Obstet Biol Reprod (Paris) 2004, 33:623-631.

48. Seng JS, Schrot JA, van De Ven C, Liberzon I: Service use data analysis of pre-pregnancy psychiatric and somatic diagnoses in women with hyperemesis gravidarum. J Psychosom Obstet Gynaecol 2007, 28:209-217.

49. Kirk E, Papageorghiou AT, Condous G, Bottomley C, Bourne T: Hyperemesis gravidarum: is an ultrasound scan necessary? Hum Reprod 2006, 21:2440-2442.

50. Adler RH: Anamnese und körperliche Untersuchung. In Psychosomatische Medizin:Modelle ärztlichen Denkens und Handelns Edited by: Uexküll T. Munich/Jena: Elsevier; 2008:397-412.

51. Wenderlin JM: Hyperemesis as a psychosomatisches problem. In Psychosomatische Geburtshilfe und Gynäkologie Edited by: Stauber M Berlin: Springer; 1999:117-124.

52. Lacasse A, Rey E, Ferreira E, Morin C, Berard A: Validity of a modified Pregnancy-Unique Quantification of Emesis and Nausea (PUQE) scoring index to assess severity of nausea and vomiting of pregnancy. Am J Obstet Gynecol 2008, 198:e71-77.

53. Ebrahimi N, Maltepe C, Bournissen FG, Koren G: Nausea and vomiting of pregnancy: using the 24-hour Pregnancy-Unique Quantification of Emesis (PUQE-24) scale. J Obstet Gynaecol Can 2009, 31(9):803-807.

54. Power Z, Campbell M, Kilcoyne P, Kitchener H, Waterman H: The Hyperemesis Impact of Symptoms Questionnaire: development and validation of a clinical tool. Int J Nurs Stud 2010, 47(1):67-77.

55. Jednak M, Shadigian EM, Kim MS, Woods ML, Hooper FG, Owyang C, Hasler WL: Protein meals reduce nausea and gastric slow wave dysrhythmic activity in first trimester pregnancy. Am J Physiol 1999, 277(4 Pt1):G855-861.

56. Reichmann JP, Kirkbride MS: Nausea and vomiting of pregnancy: cost effective pharmacologic treatments. Manag Care 2008, 17:41-45.

57. World MJ: Ondansetron and hyperemesis gravidarum. Lancet 1993, 341(8838): 185

58. Einarson A, Maltepe C, Navioz Y, Kennedy D, Tan MP, Koren G: The safety of ondansetron for nausea and vomiting of pregnancy: a prospective comparative study. BJOG 2004, 111:940-943.

59. Matok I, Gorodischer R, Koren G, Sheiner E, Wiznitzer A, Levy A: The safety of metoclopramide use in the first trimester of pregnancy. NEngl J Med 2009, 360(24):2528-35.

60. Sahakian V, Rouse D, Sipes S, Rose N, Niebyl J: Vitamin B6 is effective therapy for nausea and vomiting of pregnancy: a randomized, doubleblind placebo-controlled study. Obstet Gynecol 1991, 78:33-36.

61. Shrim A, Boskovic R, Maltepe C, Navios Y, Garcia-Bournissen F, Koren G: Pregnancy outcome following use of large doses of vitamin B6 in the first trimester. J Obstet Gynaecol 2006, 26(8):749-751.

62. Einarson A, Maltepe C, Boskovic R, Koren G: Treatment of nausea and vomiting in pregnancy: an updated algorithm. Can Fam Physician 2007, 53(12):2109-2111

63. Tan PC, Yow CM, Omar SZ: A placebo-controlled trial of oral pyridoxine in hyperemesis gravidarum. Gynecol Obstet Invest 2009, 67:151-157.
64. Leathem AM: Safety and efficacy of antiemetics used to treat nausea and vomiting in pregnancy. Clin Pharm 1986, 5:660-668.

65. Ditto A, Morgante G, la Marca A, De Leo V: Evaluation of treatment of hyperemesis gravidarum using parenteral fluid with or without diazepam. A randomized study. Gynecol Obstet Invest 1999, 48:232-236.

66. Tasci Y, Demir B, Dilbaz S, Haberal A: Use of diazepam for hyperemesis gravidarum. J Matern Fetal Neonatal Med 2009, 22:353-356.

67. Schwarzer V, Heep A, Gembruch U, Rohde A: Treatment resistant hyperemesis gravidarum in a patient with type 1 diabetes mellitus: neonatal withdrawal symptoms after successful antiemetic therapy with mirtazapine. Arch Gynecol Obstet 2008, 277(1):67-69.

68. de Aloysio D, Penacchioni P: Morning sickness control in early pregnancy by Neiguan point acupressure. Obstet Gynecol 1992, 80:852-854

69. Shin HS, Song YA, Seo S: Effect of Nei-Guan point (P6) acupressure on ketonuria levels, nausea and vomiting in women with hyperemesis gravidarum. J Adv Nurs 2007, 59:510-519.

70. Vutyavanich T, Kraisarin T, Ruangsri R: Ginger for nausea and vomiting in pregnancy: randomized, double-masked, placebo-controlled trial. Obstet Gynecol 2001, 97:577-582.

71. Portnoi G, Chng LA, Karimi-Tabesh L, Koren G, Tan MP, Einarson A: Prospective comparative study of the safety and effectiveness of ginger for the treatment of nausea and vomiting in pregnancy. Am J Obstet Gynecol 2003, 189(5):1374-1377.

72. Nordeng H, Havnen GC: Use of herbal drugs in pregnancy: a survey among 400 norwegian women. Pharmacoepidemiol Drug Saf 2004, 13(6):371-380.

73. Borrelli F, Capasso R, Aviello G, Pittler MH, Izzo AA: Effectiveness and safety of ginger in the treatment of pregnancy-induced nausea and vomiting. Obstet Gynecol 2005, 105(4):849-856.

74. Mills E, Duguoa JJ, Perri D, Koren G: Herbal medicines in pregnancy and lactation: an evidence-based approach. New York: Taylor and Francis; 2006

75. Ozgoli G, Goli M, Simbar M: Effects of ginger capsules on pregnancy, nausea, and vomiting. J Altern Complement Med 2009, 15(3):243-246.

76. Holmgren C, Aagaard-Tillery KM, Silver RM, Porter TF, Varner M Hyperemesis in pregnancy: an evaluation of treatment strategies with maternal and neonatal outcomes. Am J Obstet Gynecol 2008, 198:. 56 e51-54.

77. Nuthalapaty FS, Beck MM, Mabie WC: Complications of central venous catheters during pregnancy and postpartum: a case series. Am J Obstet Gyneco 2009, 201(3): 311.e1-5.

78. Ogura JM, Francois KE, Perlow JH, Elliott JP: Complications associated with peripherally inserted central catheter use during pregnancy. Am J Obstet Gynecol 2003, 188(5):1223-1225

79. Hsu JJ, Clark-Glena R, Nelson DK, Kim CH: Nasogastric enteral feeding in the management of hyperemesis gravidarum. Obstet Gynecol 1996, 88:343-6.

80. van de Ven $\mathrm{CJ}$ : Nasogastric enteral feeding in hyperemesis gravidarum. Lancet 1997, 349(9050):445-446.

81. Gill SK, O'Brien L, Koren G: The safety of histamine $2(\mathrm{H} 2)$ blockers in pregnancy: a meta-analysis. Dig Dis Sci 2009, 54(9):1835-1838.

82. Gill SK, et al:: The safety of proton pump inhibitors (PPIs) in pregnancy: a meta-analysis. Am J Gastroenterol 2009, 104(6):1541-1545.

83. Gill SK, et al:: The effect of acid-reducing pharmacotherapy on the severity of nausea and vomiting of pregnancy. Obstet Gynecol Int 2009:1-4. Article ID 585269

84. Nelson-Piercy C, Fayers P, de Swiet M: Randomised, double-blind, placebo-controlled trial of corticosteroids for the treatment of hyperemesis gravidarum. BJOG 2001, 108:9-15.

85. Levine MG, Esser D: Total parenteral nutrition for the treatment of severe hyperemesis gravidarum: maternal nutritional effects and fetal outcome. Obstet Gynecol 1988, 72(1):102-107.

86. Ismail SK, Kenny L: Review on hyperemesis gravidarum. Best Pract Res Clin Gastroenterol 2007, 21(5):755-769.

87. Leeners B, Sauer I, Rath W: Nausea and vomiting in early pregnancy/ hyperemesis gravidarum. Current status of psychosomatic factors. $Z$ Geburtshilfe Neonatol 2000, 204:128-134.

88. Weigel RM, Weigel MM: Nausea and vomiting of early pregnancy and pregnancy outcome. A meta-analytical review. Br J Obstet Gynaecol 1989, 96:1312-1318. 
89. Tsang IS, Katz VL, Wells SD: Maternal and fetal outcomes in hyperemesis gravidarum. Int J Gynaecol Obstet 1996, 55:231-235.

90. Brandes JM: First-trimester nausea and vomiting as related to outcome of pregnancy. Obstet Gynecol 1967, 30:427-431.

91. O'Brien B, Naber S: Nausea and vomiting during pregnancy: effects on the quality of women's lives. Birth 1992, 19:138-143.

92. Piwko C, Ungar WJ, Einarson TR, Wolpin J, Koren G: The weekly cost of nausea and vomiting of pregnancy for women calling the Toronto Motherisk Program. Curr Med Res Opin 2007, 23(4):833-840.

93. Netravathi $M$, Sinha S, Taly AB, Bindu PS, Bharath RD: Hyperemesis gravidarum induced Wernicke's encephalopathy: serial clinical, electrophysiological and MR imaging observations. J Neurol Sci 2009, 284:214-216.

94. Zhang J, Cai WW: Severe vomiting during pregnancy: antenatal correlates and fetal outcomes. Epidemiology 1991, 2:454-457.

95. Francini-Pesenti F, Brocadello F, Manara R, Santelli L, Laroni A, Caregaro L: Wernicke's syndrome during parenteral feeding: not an unusual complication. Nutrition 2009, 25:142-146.

96. Goodwin TM: Nausea and vomiting of pregnancy: an obstetric syndrome. Am J Obstet Gynecol 2002, 186(Suppl 5):184-189.

97. Power ML, Milligan LA, Schulkin J: Managing nausea and vomiting of pregnancy: a survey of obstetrician-gynecologists. J Reprod Med 2007 52:922-928

98. Atanackovic G, Navioz Y, Moretti ME, Koren G: The safety of higher than standard dose of doxylamine-pyridoxine (Diclectin) for nausea and vomiting of pregnancy. J ClinPharmacol 2001, 41(8):842-845.

Pre-publication history

The pre-publication history for this paper can be accessed here: http://www.biomedcentral.com/1741-7015/8/46/prepub

doi: 10.1186/1741-7015-8-46

Cite this article as: Jueckstock et al., Managing hyperemesis gravidarum: a multimodal challenge BMC Medicine 2010, 8:46

Submit your next manuscript to BioMed Centra and take full advantage of:

- Convenient online submission

- Thorough peer review

- No space constraints or color figure charges

- Immediate publication on acceptance

- Inclusion in PubMed, CAS, Scopus and Google Scholar

- Research which is freely available for redistribution

Submit your manuscript at www.biomedcentral.com/submit
C) BioMed Central 